$\begin{array}{ll} & \text { Etnográfica } \\ \text { etnográfica } & \text { Revista do Centro em Rede de Investigação em }\end{array}$

Antropologia

vol. $16(2) \mid 2012$

Vol. $16(2)$

\title{
Categorías de adscripción y dinámicas políticas en el norte patagónico a partir de la explotación de hidrocarburos
}

Categories of adscription and political dynamics at North Patagonia starting from the hydrocarbon exploitation

\section{Analía García}

\section{(Q) OpenEdition}

\section{Journals}

Edición electrónica

URL: https://journals.openedition.org/etnografica/1508

DOI: 10.4000/etnografica.1508

ISSN: 2182-2891

\section{Editor}

Centro em Rede de Investigação em Antropologia

Edición impresa

Fecha de publicación: 1 junio 2012

Paginación: 291-313

ISSN: 0873-6561

\section{Referencia electrónica}

Analía García, «Categorías de adscripción y dinámicas políticas en el norte patagónico a partir de la explotación de hidrocarburos», Etnográfica [En línea], vol. 16 (2) | 2012, Publicado el 26 junio 2012, consultado el 12 febrero 2022. URL: http://journals.openedition.org/etnografica/1508 ; DOI: https:// doi.org/10.4000/etnografica.1508

\section{(c) (†) 8}

Etnográfica is licensed under a Creative Commons Attribution-NonCommercial 4.0 International License. 


\section{Categorías de adscripción y dinámicas políticas en el norte patagónico a partir de la explotación de hidrocarburos}

\section{Analía García}

Buta Ranquil es un pueblo de la Patagonia argentina centrado en una ganadería de autosubsistencia donde, a principios de siglo, se inicia la explotación hidrocarburífera en un yacimiento aledaño. Las obras de construcción civil relacionadas con la producción de petróleo dan paso al arribo migratorio de obreros. En poco tiempo, se altera el estilo de vida tradicional y contrasta con la nueva dinámica social que trae aparejada la industria y el comercio. En el presente artículo, el objetivo es analizar cómo operan categorías de adscripción avaladas consuetudinariamente entre los pobladores originarios y la población migrante observando la dinámica política. Estas categorías de adscripción son de marcos conceptuales y estigmatizadores donde se sitúa la distancia social entre migrantes y originarios. Retomamos categorías antropológicas como las de "rumor" y "reputación" a fin de comprender de qué manera la experiencia social del nuevo contexto productivo impacta sobre el entramado sociocultural preexistente. Finalmente, sostendremos que las afinidades personales con base en estas categorías tensionan el cotidiano de alianzas políticas definidas en marcos regionales más amplios.

PALABRAS CLAVE: categorías de adscripción, dinámica política, cambio social, estigma.

Categories of adscription and political dynamics at North Patagonia starting from the hydrocarbon exploitation - At the beginning of the 21 th century, hydrocarbon exploitation began in Buta Ranquil, an Argentine village situated in north Patagonia and grounded on a traditional peasant subsistence economy. There, civil construction related with oil production started and promoted the arrival of migrant workmen. In a very short period of time, the traditional peasant's way of life started to change and contrast with the new social dynamics that the industry and commerce brought along. In this article, the objective is to analyze how consuetudinary categories of adscription work in a context of social change between the original inhabitants and migrants, focusing on the political dynamics. We argue that these categories serve as frameworks in which social distance regarding newcomers is part of a process of stigmatization. In addition, working with anthropological categories such as "rumor" and "reputation" enables us to understand how the new productive context impacts the pre-existing socio-cultural framework. Finally, we will argue that personal affinities based on these categories of adscription stress political alliances built over regional frames.

KEYWORDS: categories of adscription, political dynamic, social change, stigma.

GARCÍA, Analía (analiagarcia9@gmail.com) - Consejo Nacional de Investigación en Ciencia y Tecnología (Conicet); Facultad de Filosofía y Letras, Universidad de Buenos Aires, Argentina 
"Y ahí el intendente le dijo al de YPF que no quería que vinieran porque nos iban a embarazar a nuestras mujeres."

ESTE ARTÍCULO TIENE POR OBJETIVO REFLEXIONAR RESPECTO DE LAS lecturas sociales que circulan en un pueblo campesino - Buta Ranquil - a partir de la explotación de hidrocarburos en un yacimiento aledaño. Partimos de la apreciación de los pobladores originarios que experimentan este proceso de cambio social como amenazante al orden establecido ya que configura un contexto migratorio conformado por hombres solos que se trasladan para trabajar con altos niveles salariales y un "estilo de vida" cuestionable frente a la tradicional forma de interacción que prevalecía en el pueblo. Sostendremos que esta experiencia social es interpretada por los sujetos a partir de categorías sociales preexistentes que sustentan la estigmatización de los foráneos pero que también sirven a un proceso de auto-estigmatización de los pobladores originarios y que es previo a la transformación social. Puntualizamos en dinámicas y figuras políticas que permiten poner de relieve de qué manera estas lecturas locales inciden en los aspectos materiales de la cultura.

La extrañeza percibida por los "butaranquilenses" frente a la explotación hidrocarburífera es el punto en cuestión que condiciona las relaciones sociales entre vecinos. La experiencia entre el mundo campesino y el mundo obrero no sólo se circunscribe a la distancia física que impone el espacio productivo y la relación con las jefaturas sino que alberga cotidianamente la distancia social entre vecinos y regula los "contactos" entre un mundo y otro. Retomamos a Max Weber (2008 [1922]) en tanto entiende a la "comunidad" como una relación social inspirada en un sentimiento subjetivo que comprende una trama de derechos y obligaciones compartidas pero fundamentalmente que se define como un conjunto de relaciones recíprocas en donde cada individuo se considera al servicio de una totalidad que le provee, al mismo tiempo, de una dimensión de sentido a su vida.

Gran parte del análisis se inspira en el modelo desarrollado por Norbert Elias y John L. Scotson (2000) entre "establecidos" y "outsiders", ya que permite reflexionar sobre la distancia social en contextos migratorios. De acuerdo con los autores, en este modelo, el grupo establecido cierra filas con respecto a nuevos habitantes. Los antiguos pobladores remarcan la distancia social a partir del grado de cohesión interna y de control comunitario (Elias y Scotson 2000: 21 ) donde los nuevos residentes no sólo son extraños para los establecidos sino que también lo son entre sí. El grupo originario reclama para sí ciertas prerrogativas y derechos fundados en su creencia en la superioridad moral del grupo frente a los recién llegados. Los forasteros son estigmatizados y una serie de mecanismos de control social se activan para evitar el contacto con este colectivo poseedor de menor virtud humana. 
Asimismo, el análisis de Elias y Scotson (2000) en una comunidad suburbana reviste interés para nuestro caso en tanto la reputación de los sujetos estigmatizados reviste un contenido moral a partir del cual las expectativas denigratorias fundamentan el peligro que representan los contactos con estos sujetos. Asimismo, estas expectativas se sustentan también en la subjetividad que los mismos sujetos estigmatizados creen poseer. En ese sentido, Goffman (2010 [1963]: 62) plantea que el hecho fundamental del proceso de estigmatización reside en que los individuos estigmatizados sostienen las mismas creencias sobre las que se apoya la ideología del estigma y sirve a los fines de situar al otro en términos de inferioridad.

En este artículo, nos interesa señalar de qué manera el universo de la política del pueblo nos ha permitido desentrañar esta experiencia social. Concentrarnos en la dinámica política no ha sido sólo una opción metodológica, sino el espacio de referencia de los sujetos para explicarse a sí mismos la experiencia social. En la investigación doctoral (García 2009), nuestro objetivo consistió en registrar la magnitud de los cambios socioculturales que provocaban los hidrocarburos en un marco transnacionalizado. Al encarar nuestro trabajo desde una perspectiva antropológica reconstruimos la "experiencia butaranquilense" sobre la base de la observación con participación, charlas informales y entrevistas en profundidad con distintos habitantes del pueblo. Al avanzar en el trabajo de campo, se fueron concatenando una serie de dispositivos sociales que ameritaron concentrarnos en la política municipal para dar cuenta de dinámicas cotidianas sobre las que era interpretada la experiencia del petróleo en aquel tradicional pueblo ganadero. ${ }^{1}$ En este marco, el objetivo del presente artículo consiste en analizar la arena política como espacio privilegiado de comprensión del fenómeno social en su conjunto centrado en las transformaciones y desigualdades surgidas a partir de la explotación de petróleo y gas.

La frase con la que comenzamos el artículo - "El intendente le dijo al de YPF que no quería que vinieran porque nos iban a embarazar a nuestras mujeres" - forma parte de una narrativa con la que "los butaranquilenses" señalan limitaciones en los contextos de interacción social entre petroleros y campesinos. Estos rumores nos motivaron a concentrarnos en el ámbito político como espacio en el que se prescriben determinados comportamientos y formas de interpretar las transformaciones socioeconómicas actuales. En particular, se narraban historias, entre públicas y privadas, sobre las que los intendentes del partido hegemónico provincial - el Movimiento Popular Neuquino (MPN) rehuían a la presencia petrolera y advertían respecto del contacto con aquel nuevo universo productivo que imprimía sus huellas en el territorio.

l El trabajo de campo se desarrollo en sucesivas experiencias entre los años 2005 y 2008, es decir habiendo pasado un tiempo del auge anteriormente mencionado. Este lapso transcurrido permitió dimensionar la concepción nativa desde una perspectiva de mediano plazo, con niveles de producción y empleo medios y con las obras de construcción civil ya concluidas. 
Nosotros sostenemos que las apreciaciones sobre este proceso de transformación son situadas dentro de marcos conceptuales preexistentes en el pueblo. Concretamente nos referimos a la forma en la que operan categorías de adscripción de las personas - "nacidos y criados" (nyc) y "venidos y criados" (vyc) - sobre el contexto migratorio. Veremos que la diferencia entre unos y otros - y la distancia social consecuente - está dada más en términos de pertenencia territorial que de identificación económico-sectorial.

Para ello, retomamos otros trabajos que abordan la caracterización de estas categorías de adscripción en el espacio de Norpatagonia. Alma Tozzini (2004) señala que se trata de marcadores que actúan como taxonomías donde los nyc se identifican con el lugar pretendiendo tener la suma de los derechos en la región. La autora señala que los "venidos" se oponen a los "nacidos" a partir de las prerrogativas que auto-asumen los segundos y las sospechas y desconfianzas que se posan sobre los primeros (2004: 25). Por su parte, Carolina Crespo sostiene que estas categorías englobadoras son clasificaciones que responden a procesos de estigmatización y discriminación internalizados que condicionan las definiciones y demarcaciones del propio grupo y de los "otros" (Crespo 2008: 229), donde orígenes migratorios, territorios de nacimiento y tiempos de arribo diferencian entre un "adentro" y un "afuera" (2008: 236). Las categorías que dirimen entre un "nosotros" asociado al espacio físico y un "extranjero" disponen el marco referencia sobre el que se ubica la dinámica de la política local. En este sentido es que las vivencias asociadas a la migración se construyen sobre categorías sociales preexistentes que recorren el espacio patagónico. En este artículo veremos de qué manera estas categorías - nyc y vyc-operan en la práctica y tienen consecuencias en el mundo material de vida, es decir, no se trata solo de categorías que se mueven en el plano ideacional de la cultura.

Trataremos con particular atención los mecanismos de control social en base a estas categorías mostrando sus propias lógicas fundadas en el nacimiento y la vecindad. Para ello, pondremos en relieve los dispositivos locales en relación con estrategias electorales de corte provincial. Al ver estas categorías en acción sobre la dinámica política, comprenderemos la magnitud de los procesos de transformación que se instituyen en la experiencia social a partir de la irrupción de nuevos actores sociales en la escena económica y política. Específicamente, nos referimos al Sindicato de Petroleros Privados (SPP). En términos metodológicos, nos interesa indagar en procesos políticos en la medida en que éstos permiten iluminar respecto de la totalidad social en la que tienen lugar. En otras palabras, hemos centrado la estrategia metodológica en "la política" como espacio del campo sociocultural en donde se explicita el proceso de transformación social. Al llevar adelante este enfoque, desarmamos la categoría de los "butaranquilenses" - en tanto que categoría homogénea con la que se iniciaron los trabajos de campo -, hecho que nos permite problematizar en torno al vínculo entre dinámicas capitalistas y construcciones territoriales. 


\section{DE PUEBLO GANADERO A PUEBLO PETROLERO}

Nos situamos en Buta Ranquil, un pueblo situado en el norte de la provincia de Neuquén, en la Patagonia argentina. En contraste con otras provincias argentinas, la explotación hidrocarburífera, la producción frutihortícola con perfil exportador y el desarrollo turístico del sur otorgan a Neuquén un perfil prolífero y moderno desde el punto de vista económico y sociocultural. Sin embargo, en el norte provincial donde se sitúa Buta Ranquil, prevalecen dinámicas regionales basadas en la ganadería trashumante de ganado menor con fines de autosubsistencia. Este contexto caracterizó a Buta Ranquil hasta principios del siglo XXI, cuando se intensifica la explotación hidrocarburífera en el yacimiento aledaño al pueblo. A partir de entonces, la vida pueblerina, nutrida de familias campesinas que conservan sus puestos de invernada y empleados públicos abocados a las tareas municipales, comienza a contrastar con las actividades industriales y comerciales que los inicios de la producción petrolera y gasífera traen aparejados.

Nuestro contacto en el pueblo se inició en el marco de la investigación doctoral, centrada en el auge productivo y el abrupto crecimiento demográfico (a tasas del 7,2\% anual acumulativo) ocasionado tras los comienzos en la explotación del yacimiento petrolero y gasífero El Portón - situado a 20 kilómetros del pueblo sobre la ruta provincial 6 -, la construcción del gasoducto Transneuquino y la construcción de la Planta de Gas Licuado de Petróleo (GLP). Estos emprendimientos se hallan controlados por YPF SA quien a su vez contrata a distintas empresas dedicadas a prestar servicios a la industria. ${ }^{2}$ Estas empresas cuentan con contingentes de trabajadores especializados que se trasladan desde otras ciudades petroleras para el desempeño de tareas que les son encomendadas. La mano de obra que ha sido contratada en el pueblo fue destinada a tareas no especializadas asociadas a las obras civiles que demandaron los comienzos de la explotación. Posteriormente, poca fuerza de trabajo oriunda logró permanecer en un empleo asociado a la producción hidrocarburífera.

En sus comienzos, los trabajadores residían en los campamentos situados a la vera del yacimiento. Sin embargo, a medida que se consolidó la producción, los campamentos fueron eliminados y en el pueblo se construyeron hoteles que dan albergue a los trabajadores durante la semana laboral. Asimismo, muchos habitantes del pueblo construyeron "piezas" y "casas" de alquiler que son contratadas por las empresas para hospedar a la fuerza de trabajo masculina. Los campamentos de las empresas, aunque ya no albergan a la mayoría

2 YPF SA es una sigla que retoma el nombre de la antigua petrolera estatal - Yacimientos Petrolíferos Fiscales. Al momento del trabajo de campo, esta empresa formaba parte del grupo petrolero Repsol, empresa de capitales españoles. 
de los trabajadores, sin embargo tienen los almacenes y comedores en que diariamente almuerzan los petroleros, de modo tal que las jornadas productivas ocurren sin que la dinámica pueblerina pareciera alterarse.

La migración temporaria que caracteriza la explotación petrolera de la región da lugar a una fragmentación de los tiempos y espacios de los obreros. Pasados los años, muchos trabajadores se han establecido en Buta Ranquil así como también se instalaron comerciantes que llegaron atraídos por el crecimiento del pueblo. Sin embargo, la mayoría de los trabajadores mantiene sus familias en sus ciudades y pueblos natales, trasladándose a Buta Ranquil durante el lapso de duración de la semana laboral. Incluso muchos trabajadores sostienen esta dinámica impuesta conformando dos núcleos familiares, uno en su ciudad natal y otro en el espacio productivo.

La política municipal conserva una dinámica asociada a los lazos personales que tradicionalmente regulan la vida en el pueblo y se sustentan en el conocimiento "cara a cara" entre vecinos. Los impactos de la producción hidrocarburífera representan una alteración de esa dinámica al tener que lidiar con el sobrepoblamiento de hombres que no guardan arraigo con el pueblo y que irrumpen en el escenario como desconocidos. Esta situación de Buta Ranquil contrasta con otros enclaves petroleros de la Cuenca Neuquina donde la explotación de este recurso no renovable motoriza los vínculos sociales y políticos que tienen lugar a partir de esta actividad económica. ${ }^{3}$

Además, la Unidad Económica El Portón - de YPF - reserva un predio cercado - la "Base Operativa" - en donde se ubican las oficinas y habitan sus empleados; cuenta con las provisiones necesarias para llevar la semana laboral en la inmensidad desértica del yacimiento. El predio habitacional que se halla dentro del yacimiento tiene cercado y seguridad propia. Lindando con las oficinas de trabajo, las canchas de paddle, la pileta de natación, el comedor y demás comodidades se encuentran dentro de la esfera productiva y son, de hecho, un espacio de reclusión, de modo tal que no existe necesidad alguna de contacto con el pueblo. Las jefaturas cuentan con lo necesario para vivir hasta volver a sus

3 Los sistemas regionales de enclave se definen como una forma de organizar la producción donde la vinculación entre el centro productor y los servicios necesarios para mantener a los trabajadores son muy estrechos. Los enclaves conforman un sistema de relaciones sociales asalariadas donde la unidad productiva principal estructura las actividades secundarias que se desenvuelven en función de las necesidades y requerimiento de la actividad principal. Los principales recursos locales y el sostenimiento de la infraestructura urbana devienen de los salarios, las demandas y los servicios que brindan las empresas del sector (Salvia y Panaia 1997: 22). El desarrollo de esta forma de organización social caracteriza los pueblos hidrocarburíferos de la Cuenca Neuquina basados en la monoactividad, que se conforman como polos de atracción poblacional dada por los altos salarios del sector. Los enclaves petroleros han sido objeto de la investigación doctoral en términos comparativos, recuperando para ello el aporte de la antropología en lo que refiere a las grandes obras de construcción civil analizadas por Gustavo Lins Ribeiro (1991, 2006) y el sistema fábrica-villa operaria propuesto por Sérgio Leite Lopes (1988). 
lugares de origen, incluidos los espacios recreativos para realizar deportes. Así el personal de YPF o los cuadros supervisores de obra que provienen de otras zonas habitan sobre el yacimiento y pueden no conocer el pueblo o tener ningún tipo de contacto con sus pobladores. De este modo, la distancia física entre el yacimiento y el pueblo conserva de modo tajante la distancia social que separa a las jefaturas no sólo del pueblo sino también de los obreros petroleros:

"Eso es un oasis. Está todo alambrado donde viven ellos, con cancha de paddle, cancha de fútbol, quincho... como viven los árabes en Arabia Saudita, igual [...] Viven muy bien, tienen el confort del primer mundo y nosotros acá no lo tenemos y lo más triste es que es con nuestros recursos" [Enrique, ex-concejal independiente].

"Vos vas al Portón y es una ciudad aparte, está todo fuera del pueblo. YPF tiene gente especializada de ellos, tiene un patio gigante, un aeropuerto, los viejos viven como en el paraíso. Tienen cancha de golf, tienen todo lo que vos le pidas, tienen cancha de tenis... No sé cómo es la ley, pero para mi entender todo lo que ha hecho Repsol o la empresa que estuviera al frente de todo esto, tendría que estar acá porque yo le puedo exigir como poblador a Repsol no solamente que me de laburo, sino que me cuide el pueblo o que me ayude para cuidar el pueblo. Yo creo que pasa más que nada por un tema político" [El Jirafa, trabajador petrolero].

Esta distancia social a partir de la cual el mundo petrolero parece tener lugar sin que las jefaturas precisen entablar vinculación con la cotidianeidad del pueblo tiene su correlato también entre los habitantes del pueblo, quienes alegan no conocer el yacimiento y observan una serie de comportamientos de evitación en relación a la dinámica petrolera. El yacimiento se presentaba como un lugar ajeno y vedado fruto de una serie de elucubraciones en torno a la apropiación privada de un espacio que "es nuestro, de los habitantes de Buta Ranquil". Salvo los horarios de salida o regreso de los trabajadores del yacimiento, la dinámica pueblerina, en apariencia, se desenvuelve sobre los lazos de la vida campesina. En Buta, hablar de petróleo puede ser un tema ríspido, casi callado y aún temeroso: "Yo quiero sacar una foto pero tengo que llevar la maquinita escondida porque si me ven... tienen todo controlado ellos".

\section{LAS CATEGORÍAS DE ADSCRIPCIÓN}

La separación entre el espacio de reproducción social de las jefaturas y el pueblo es nítida; se expresa geográficamente segmentando las relaciones sociales y limitando la intensidad de las mismas. Pero el panorama se complica cuando nos situamos en el espacio de reproducción social - el pueblo - y las relaciones 
sociales se concentran sobre la vecindad y la amistad entre "nacidos y criados" y "venidos y criados". Además de la distancia física que separa a la producción petrolera del espacio de reproducción social, se desenvuelve una versión local de vivir esta experiencia basada en categorías preexistentes.

"Fuimos formando parte de los grandes cambios de Buta Ranquil [...] Por ahí te ven que vos progresás y te critican o te hacen a un lado. Yo por ejemplo, hace diecisiete años que estoy en Buta Ranquil y todavía no formo parte de Buta Ranquil, todavía me siguen viendo que soy de afuera... y tengo un hijo que es neuquino y ama este pueblo" [Estela, comerciante de Buta Ranquil, oriunda de la provincia de Mendoza].

"Si vos te metes mucho como que sos de afuera, 'vos sos de afuera, no tenés por qué meterte’. Por más que yo hace doce años que estoy, tengo lo mismo vivido que lo que viví en San Rafael, pero siempre sos de afuera. Muchos compañeros que trabajan en la empresa me dicen: 'es la primera vez que yo voy a un pueblo, por ejemplo y que me discriminen o me apunten con el dedo como diciendo que soy de afuera porque yo vine a trabajar'. Pero es así, la gente tiene miedo, yo no sé a qué tendrá miedo" [Antonio, trabajador petrolero, oriundo de Mendoza].

La extranjería de aquella población migrante se convierte en el clivaje que separa grupos sociales. La categorías que señalan personalidades sociales operan para situar la negatividad del petróleo donde la expresión de la expansión capitalista - la actividad hidrocarburífera y el asalariamiento - se sitúa en los marcos conceptuales preexistentes de la vida social en Buta Ranquil, al activar categorías de adscripción fundadas en el origen.

En este marco distinguen "comportamientos" propios de los extranjeros que irrumpen en el escenario local y modifican la dinámica cotidiana. Como Elias y Scotson (2000) referían a la relación entre establecidos y outsiders, resulta oportuno señalar el poder de clasificación estigmatizante sobre el que la cohesión interna y el control comunitario poseído por un grupo supone la anomia del otro.

En el espacio patagónico, "la vida de los petroleros" es usualmente calificada por el resto de la sociedad a partir de ciertos rasgos donde se exacerba una "masculinidad irracional". Tres tópicos son esgrimidos como clivajes para calificar a la población petrolera: la ostentación, el desorden y el desarraigo. La ostentación es producto de formas de consumo, deja entrever que los salarios petroleros son elevados comparados con el salario del empleado público y el poder adquisitivo de las familias campesinas dedicadas a la autosubsistencia - las casas, los autos y el estilo de vida en general se rigen sobre pautas de consumo que distancian a los foráneos. Tiene un efecto contrastativo que 
permite sostener que "el derroche" de los petroleros no forma parte de un proceso de desarrollo y distribución de los recursos. En este sentido, el salario de los trabajadores tiene algo de ilegítimo, ya que el pueblo se presenta en los relatos de los nyc al margen de la experiencia asociada al desarrollo de relaciones capitalistas.

En ese sentido, la lectura de los sujetos respecto de la explotación hidrocarburífera es una crítica social fundada en su propia experiencia. La privatización de la explotación petrolera y la desregulación de la actividad ha sido y sigue siendo materia de extenso debate nacional. Implica severas reflexiones respecto del papel que juegan las grandes multinacionales (Azpiazu 2005; Mansilla 2007) y de los efectos sobre los territorios que se convierten en "meras plataformas extractivas" sin vínculos con el mundo social (Landriscini y Laría 1999; Colantuono 2001). Tanto a nivel nacional como regional, las condiciones de explotación de recursos no renovables y las condiciones para promover el desarrollo son tópicos comunes de una agenda pública basada en la explotación de ventajas comparativas naturales como lo es la estructura económica argentina. Sin embargo, a nivel local - desde la óptica de los sujetos - implica que se trata mucho menos de monopolios, de falta de inversión y de políticas de precios usureras y más de desigualdades sociales en los márgenes de vida sobre los que parientes, amigos, compañeros y vecinos - nyc o vyc-acreditan un estado de cosas. No es que nada de este proceso macroeconómico sobrevuele el territorio sin afectarlo; al contrario, el entramado social solo deviene en tal como consecuencia del mismo. Sin embargo, lo que está en juego es más que un discurso político, una toma de posición ideológica o una apreciación basada en supuestos racionales; son las relaciones sociales concretas sobre las que cotidianamente la dinámica local experimenta la desigualdad. Desde esta mirada microscópica de la vida social, el universo de los "butaranquilenses" remite al problema de la apropiación y explotación de la naturaleza como un problema social local. Más concretamente, entre vecinos, el ojo está puesto no en la explotación petrolera en general sino en el proceso social de producción, que expresa a través del acceso diferencial a los recursos - valorados localmente a través de los salarios y la infraestructura - la desigualdad instalada a partir de su aparición. En este plano, quienes se posicionan desde una pertenencia de tiempos prolongados y generaciones locales - los nyc - no están cuestionando al objeto en sí mismo sino las condiciones que lo hacen posible y que condicionan las demarcaciones entre unos y otros.

El desorden se funda en prácticas culturales que caracterizan las intensas semanas laborales de los hombres petroleros alejados de sus familias y reviste una apreciación moral sobre la que se funda la evitación en los "contactos mixtos", parafraseando a Goffman (2009 [1959]). Al tratarse de enclaves que demandan en mayor parte la atención de población masculina de origen migrante dedicada a labores pesadas, se delinea una geografía humana fundada 
en la estigmatización de su performance de interacción. El imaginario social dibuja una "brutalidad" irracional: manejan rápido en grandes camionetas, seducen a muchachas jóvenes y las embarazan (aún cuando tienen su familia en otra ciudad), se dedican a gastar sus salarios en el juego, se emborrachan en sus ratos libres, en fin, una serie de elucubraciones estigmatizantes con asiento en una performance de la vida laboral fundada en la separación existente entre los tiempos de trabajo y los tiempos de no trabajo. Por poner el caso, las casas de prostitución son características de estos enclaves petroleros en pos de atender los requerimientos de hombres solos. En Buta Ranquil, esta "necesidad" fue motivo de polémica en relación a cómo abordar la problemática.

"Surgió un problema con el cabaret porque estaba dentro del radio urbano y la ordenanza dice que tiene que estar a cinco kilómetros. Y jodía mucho a los vecinos porque era de lunes a lunes con los líos que trae: el tema de los autos, de la borrachera, de la música. Hubieron varias quejas" [Gastón, concejal].

Como remarca Sayad (1999 [1993]: 27), las formas discursivas sobre las que se traza un sentido de pertenencia y exclusión remarcan la idea que cada cual se hace de sí mismo en términos de su identidad social. ${ }^{4}$ En este plano, distancia física y distancia social no son la misma cosa. Aún siendo vecinos, los antiguos pobladores y los recién llegados vinculados al mundo petrolero se encuentran alejados socialmente. En términos de Goffman (2010 [1963]), el defecto de carácter de los petroleros también contiene un tinte deshumanizante: sus comportamientos se rigen por una "brutalidad" que los aleja de los modales y formas de comportarse respetuosas del orden humano en el que se insertan.

Estas categorías nativas forman parte del acervo cultural con el que los sujetos elaboran la trama de su vida social presente e instituyen simbólicamente formas de conducirse sobre el nuevo escenario productivo, de comportarse y de considerar al otro, pero también de considerarse a sí mismos. El estigma de los "petroleros" y de los extranjeros atraídos por dinámica del mercado capitalista local deviene más que un factor basado en un sentimiento de superioridad de los $n y c$, en un mecanismo de repliegue sobre un estrepitoso avance de las relaciones asalariadas y las transformaciones consecuentes incluso en el ámbito político. El petróleo recibe la condena de ser una fuente de riquezas que son expropiadas, apropiadas por un otro genérico y alejado, que representa la compañía de capitales españoles Repsol. Pero, al mismo tiempo, despierta sentimientos asociados a la cercanía de su presencia, el "barrio privado" de YPF

4 Sayad (1999 [1993]) reconstruye las entrevistas sostenidas con vecinos de un barrio de la periferia parisina, subrayando el pensar y el sentir de una señora "francesa" frente a sus vecinos, una familia de padres árabes e hijos de éstos nacidos en Francia. 
- como es llamada la Base Operativa -, expresa la desigualdad sobre la que se cierne la divisoria de aguas respecto de un "otro" cercano, entre vecinos.

Sayad demuestra que quien se arroga la representatividad en cierto modo "auténtica" - "francesa" en el caso que analiza el autor - referida al territorio en cuestión supone un discurso que se sitúa en defensa de ciertos intereses materiales y simbólicos sentidos como exclusivos de un sector particular de la población. Supone "cualidades que dan derecho a un hábitat reservado", al mismo tiempo que indignación y protesta, "por verse obligada a sufrir una cohabitación percibida como degradante, humillante, con una población en sí misma degradada, despreciada, desvalorizada" (Sayad 1999 [1993]: 28). En nuestro caso, lo que atraviesa la divisoria es la "amenaza" al orden establecido previamente y que, de modo contradictorio, remarca en términos estigmatizantes a la condición del propio grupo, es decir de los nyc. "Siempre el de acá es el indio que no sabe nada", insisten en sucesivas entrevistas los hombres adultos de Buta Ranquil. En este sentido, la "experiencia butaranquilense" remarca en el poder taxativo de las categorías de adscripción porque los sujetos reflexionan que "la oportunidad que perdieron" con la explotación petrolera es consecuencia de su propia identidad social. En la experiencia de campo, los mismos sujetos que condenaban moralmente las interacciones con el mundo petrolero subrayaban la falta de avidez política para conducir el proceso de transformación económica en beneficio del crecimiento del pueblo. Comparaban con otros enclaves petroleros de la región y alegaban no haber podido capitalizar la experiencia para potenciar el desarrollo, fundamentalmente en materia de infraestructura de servicios públicos y mejoramiento de la calidad de vida de la población en general. En este sentido, el proceso de estigmatización no puede escindirse de las relaciones de dominación bajo las cuales el propio grupo es también objeto de un proceso similar. La ideología del estigma supone la infravaloración de los extranjeros y es parte de una dinámica donde el objetivo es preservar la identidad del grupo, afirmando cierta superioridad moral frente a un contexto material amenazante y de extrema vulnerabilidad. Pero, la forma en que el grupo estigmatiza al otro se sitúa en una escala de "humanidad" que parte de reconocer la estigmatización de sí mismos por parte de la sociedad en general. Estipula comportamientos de evitación frente al grupo estigmatizado pero también se convierte en objeto de reflexión y de victimización que fortalecen una identidad grupal infravalorizada.

Por último, el tercer clivaje sobre la estigmatización de los extranjeros - el desarraigo - permite esgrimir ciertas prerrogativas sobre el espacio y sobre el manejo de recursos materiales. En tanto que los petroleros son observados en el marco de cierta provisoriedad - "vienen, construyen, todo para tener algo, pero siempre están pensando en volver a su pago" ${ }^{5}$ - la condición del ejercicio 
de derechos de origen extiende las condiciones estigmatizantes sobre todos los extranjeros. Al principio del apartado señalamos la cita de la comerciante que junto con su hijo (nacido en el pueblo) es señalada como ajena a ciertos espacios de la vida social reclamados por quienes se arrogan el derecho de nacimiento. El actual intendente planteaba la siguiente paradoja: "yo siempre digo que tendría que tener la bola de cristal, porque me dicen "yo hace dos años que estoy acá y no puedo conseguir un terreno'. ¿Y cómo sé yo que el que viene a edificar, viene con buenas intenciones?" En términos de Goffman (2010 [1963]: 61-68), la información social que "maneja" el intendente no se sustenta en el conocimiento de la persona sino que ésta es, en principio, virtualmente desacreditable por cuanto su comportamiento - o las desconfianzas respecto de él - se sujetan falsamente en la identidad social que se construye sobre el grupo estigmatizado. A modo de ejemplo, así se refería respecto de los extranjeros y los problemas asociados a la distribución de recursos de asistencia social:

"Hay gente que vino de afuera, de provincias donde no existe este tipo de ayudas. Y viene acá y lo exige [...] Y se los tenemos que dar iA quién se lo tengo que sacar? Porque a mi me dan siempre lo mismo. Se lo tengo que sacar al de acá, que lo recibió siempre pero que por ahí está un poquito mejor económicamente. No es que seamos tontos los de acá pero el que viene de afuera tiene más labia, sabe manejarse mejor. ${ }^{6}$ Con el de acá puedo ir tirando pero con el de afuera por ahí me quema los bolsos afuera (en la intendencia). Te crea otros problemas, [necesita un terreno para construir la vivienda] y se instala en el camping, en la plaza..."

En definitiva, cualquier extranjero, "la gente que vino de afuera" es objeto de desconfianzas por cuanto representa una identidad social disruptiva del orden social (podría instalar su casa en la plaza) y probablemente peligrosa en lo que refiere a la paz social reinante (podría iniciar una protesta social). En ese sentido, las lecturas nativas no son meras interpretaciones, tamices sobre los cuales pensarse a sí mismos y al proceso de transformación. También instituyen comportamientos y actitudes hacia las personas y las cosas. Es decir que no son sólo ideacionales sino que devienen en dispositivos de control que sirven para articular la práctica y tienen efectos en la materialidad de la vida cotidiana.

6 "Labia" es un término coloquial para significar el efecto de convencimiento de un discurso. "Tener labia" es construir un discurso con una retórica argumentativa que se impone frente al auditorio y pese a las resistencias, logra convencer. 


\section{LAS INVASIONES BÁRBARAS: RUMORES DE EVITACIÓN}

Al concentrarnos en los procesos de transformación social, trabajamos con las apreciaciones que tienen los sujetos referidas a las relaciones sociales que se expresan a partir de esta experiencia. Los sujetos señalan el locus del problema a partir de las apreciaciones que tienen de los políticos y que éstos tienen en relación con la producción de hidrocarburos. En este marco, la vivencia petrolera no solo refería a la producción de discursos y recreación de categorías simbólicas sino que también inicidía en las prácticas sociales.

Como recurso retórico, apelaremos al proceso de construcción etnográfica. Al comenzar la investigación incurrí en experiencias de campo en otras zonas de la provincia de Neuquén. En esos tiempos, visitaba también la capital neuquina con el fin de recabar fuentes de información secundaria y preparar la selección de emplazamientos de campo. Aprovechaba la oportunidad para visitar conocidos que hacían las veces de orientadores en mis tareas de búsqueda. Principalmente, solía recurrir a la ayuda de una persona en particular que colabora a la distancia con las actividades del equipo de investigación al que pertenezco. Entre charla y charla, sugirió que Buta Ranquil podía ser un caso especial para abordar en torno al impacto de la explotación del petróleo. Aclaró que se trataba de un pueblo “típico" del norte neuquino, dedicado a la ganadería, tras lo que mencionó que había muchos "problemas por el embarazo de mujeres adolescentes". Suponía que esto era un síntoma de las consecuencias de la migración de petroleros. Unas líneas más arriba apelamos a citas que presentaban la problemática de jóvenes madres solteras en el mismo sentido en que lo hacía mi "orientador de campo". El rumor había llegado a oídos de todos, aún por fuera de la escena local.

Entre los años 1995 y 1999, Paco Calderón, nacido y criado en Buta Ranquil, fue intendente del pueblo, elegido por el partido provincial. A él se lo recuerda cómo el intendente que le dijo que "no" a la YPF. Los relatos apelan a un gerente de la petrolera que se acercó al pueblo para planear la Base Operativa sobre el radio urbano, aquel "barrio privado donde viven con todos los lujos". Solicitaba la cesión de tierras para organizar la vida de las jerarquías aprovechando algunas de las ventajas en infraestructura de un pueblo ya constituido. Pero según la narrativa local, el intendente Paco Calderón respondió con una negativa que los confinó al yacimiento que se encuentra en explotación, a 20 kilómetros. El motivo argüido por el funcionario público era el riesgo que se corría de "facilitar embarazos no deseados en las mujeres del pueblo". Resignó el asfalto, los campamentos de las tercerizadas, mayor intensidad en la vida comercial, la red eléctrica, gasífera y cloacal, la construcción de espacios recreativos, la instalación de una red de telecomunicaciones y vaya a saber cuántas cosas más que los "butaranquilenses" lamentan que podrían haber sido posibles si la unidad productiva y reproductiva hubiesen sellado lazos urbanos comunes. De acuerdo 
con la explicación local, la decisión política de impedir que las instalaciones petroleras quedaran en la ciudad focalizaba en uno de los tópicos sobre los que se configura el estigma de los petroleros: el desorden basado en la dudosa moralidad del estilo de vida de los migrantes. Pero asimismo, tras sucesivas visitas al campo, descubrí que este rumor circula en el espacio patagónico como una anécdota entre patética y risueña a la que se apela para estigmatizar una "mentalidad tradicional" que caracterizaría el espíritu de proyección política de los funcionarios de Buta Ranquil. En esos términos, el proceso de estigmatización se invierte. Para quienes conocen la explotación petrolera en la provincia, el estigma recae sobre los representantes políticos de "los butaranquilenses" ahora en un sentido limitado a los "nacidos y criados" - en tanto reniegan de la "modernización", producto del desarrollo de la actividad industrial.

Como planteamos más arriba, quienes apelan al estigma de la "brutalidad" de los trabajadores petroleros construyen en los mismos relatos su propio estigma: relatan la anécdota de Don Paco casi horrorizados por las consecuencias de semejante decisión. En este sentido, no nos concentramos en rastrear la construcción del "rumor" en términos de su relación con las estadísticas de embarazos de madres solteras, o qué es consecuencia de qué otra cosa. Pero sí consideramos central que el "rumor" deviene verosímil para los sujetos. A partir de entonces, el pueblo da lugar a la segregación espacial evidente entre la naciente villa obrera y el lugar de residencia de las jerarquías empresariales sobre el territorio en donde "el rechazo empezó por acá. Ellos quisieron acercarse pero el rechazo empezó por acá”. ${ }^{7}$

Como plantea Bailey (1971), el "rumor" puede constituirse como un dispositivo de control social que permite articular cierta idea de cómo son las cosas y cómo deberían ser. En definitiva, el mítico encuentro entre Paco Calderón y "la YPF" prescribe sobre ciertos comportamientos en torno a la amenaza de desorden que implica asociarse a estos capitales. Parafraseando a Elias (2003), los "petroleros" se convierten en "un medio de polución". En efecto, mezclarse con ellos a través de la descendencia para las mujeres o convertirse en uno abandonando las actividades ganaderas para los hombres jóvenes, enriquecerse con hoteles y servicios brindados a las empresas, aparece en los dichos de los "butaranquilenses" como factores de "contaminación". De allí que encontramos que las actividades petroleras se sitúan en los discursos y disposiciones de los sujetos como un material vedado, callado y alejado como aquel temor a sacar una foto, recorrer el espacio productivo o aún entrar en contacto con el personal de la jerarquía empresarial.

7 Claro que en El Portón se escuchan otras voces que aunque reproducen este discurso, también "conocen" la otra vereda: "Si Repsol vivía allá con su grupo de trabajo, tenía asfalto, querían asfaltar hasta el pueblo, ¿entendés? Pero después vino otro señor de Repsol, es gallego, directamente mandado por Repsol de España. Entonces él aducía que no venía a arreglarle la calle a los argentinos" [ingeniero en El Portón]. 
A Paco Calderón le sucede su colega Pedro Alvarez, en un contexto de pleno auge en materia de explotación del yacimiento. ${ }^{8}$ En ese entonces comienza a circular un nuevo "rumor" que tiene por protagonistas a Alvarez y al señor Maggio, gerente de la Base Operativa. Los dichos aseguran que Maggio tenía la voluntad de "hacer las cosas distintas y beneficiar al pueblo", ya que se había casado con una chica de Buta y proponía actividades y obras que podían promover el desarrollo de infraestructura. Se dice que esta vez el intendente le negó cualquier tipo de intervención sobre la escena local "por miedo" a que las dádivas empresariales convirtieran al señor Maggio en un candidato a la competencia política y terminase por usurpar la intendencia.

"Hubo intentos de acercamiento para hacer una escuela pero para ellos [los políticos] era que querían hacer política iPero qué política puede hacer una persona que era superintendente en el área del Portón! Cobraba doce mil, creo. No tiene comparación con un intendente, que cobraría mil pesos" [Sandra Fernández, concejal].

El resultado de esta situación fue que se terminó por cerrar filas a cualquier "mezcla" cuando Maggio fue trasladado a Comodoro Rivadavia y ningún gerente volvió a "tocar las puertas" de la intendencia. En este sentido, el rumor - más allá de su veracidad - es en sí mismo un hecho social en tanto deviene verosímil para los sujetos y configura el estado social de las cosas. Si se dice que sucesivos intendentes "negaron" toda tentativa de vinculación con las empresas operadoras, estos dichos no pueden aislarse del contexto económico y sociocultural en que son producidos. Particularmente, el modelo de categorización y de adscripción subyace y circula sobre los "rumores" e inaugura la aprehensión a los "petroleros" como "medio de polución". La amenaza que representa la población masculina afamada en una moralidad repudiable por los nacidos y criados es un tópico inicial de la evitación. Sin embargo, el extranjero es descalificado en una narrativa en la cual la crítica social refuerza el estigma que se tiene sobre los "nacidos y criados". Es decir que se apela a otro externo y cuestionable pero en un marco de interpretación donde el originario es, finalmente, el sujeto puesto en cuestión. Los rumores son narrados en contextos discursivos en los que se hace hincapié en la liturgia del "tradicionalismo" que caracteriza el "atraso" del pueblo liderado por los nyc.

"Yo lo viví porque formé parte de una comisión femenina donde se peleaba por el gas. Fuimos con el intendente de ese momento a Repsol [YPF]. Cuando llegamos, las mujeres que habíamos ido nos bajamos de la

8 No está de más aclarar que todos los intendentes de Buta Ranquil hasta la fecha han sido "nacidos y criados" y representantes del partido hegemónico provincial. 
camioneta y entramos. Nos damos vuelta para presentar que veníamos con el intendente de la localidad y cuando nos damos vuelta para presentarlo, no estaba... '¿Y dónde está?, ¿¿ónde está?’ Miramos y estaba en el estacionamiento, no nos había seguido... por vergüenza, por no saber expresarse, llamalo como quieras. Si a vos te dieron un puesto donde te dieron un cargo y te dieron la responsabilidad en lugar de ir atrás nuestro, tenés que ir adelante. Entonces Buta Ranquil está, en ese sentido, está como está por todos los gobiernos que ha tenido" [Estela, comerciante de Buta Ranquil].

La cita de Estela hace evidente el punto en cuestión: posiciona a los sujetos como responsables del estado actual de cosas, reforzando apreciaciones que menoscaban la apreciación que "los butaranquilenses" tienen sobre sí mismos. El nyc convertido en intendente es aquel "que se queda atrás", acusado por la "vergüenza" o por "no saber expresarse". De modo tal que si las cosas son como son y no satisfacen las expectativas de los pobladores, el causal de las desgracias deviene del interior de la localidad y no de las condicionalidades externas. Aunque el "petrolero" y el petróleo representan una amenaza de desorden y transformación, son sus propias acciones - las internas - las que confirman y potencian dicha desigualdad.

\section{LA DINÁMICA DE LAS CATEGORÍAS Y LAS REPUTACIONES EN JUEGO}

Hasta aquí es posible comprender que las diferentes categorías de persona constituyen dispositivos locales sobre los que situar la experiencia y prescribir comportamientos, actitudes y deseos colectivos. Sin embargo, aún nos resta profundizar en los mecanismos concretos a partir de los cuales el grupo de establecidos - al decir de Elias - cierra filas frente a la competencia política de los extranjeros ¿De qué manera estos relatos constituyen algo más que una interpretación y permiten sostener que los "nacidos y criados" autoasumen prerrogativas frente a los outsiders?

En el transcurso del 2007 en Neuquén hubo elecciones ejecutivas y legislativas para cubrir cargos provinciales y municipales. En la provincia, el armado electoral del partido hegemónico provincial - el Movimiento Popular Neuquino - incluyó candidatos del sindicato de petroleros manifestando públicamente una alianza política. En las listas municipales, los principales referentes sindicales encabezaron las listas ejecutivas y/o legislativas. Esta alianza se reprodujo en Buta Ranquil, donde el intendente buscó la reelección y presentó como primer candidato a legislador al delegado regional del sindicato. El triunfo de esta alianza quedó plasmado tanto en nivel provincial como municipal. Sin embargo, en el municipio, la suma de votos opositores se duplicó con respecto a la elección anterior. La composición del Consejo Deliberante quedó conformada por cuatro representantes opositores y tres representantes de la lista ofi- 
cial, encabezada por el sindicalista. Salvo este último, todos los representantes legislativos resultaron ser "nacidos y criados", al igual que el intendente. ${ }^{9}$

Por primera vez, un extranjero - "venido de afuera" - pasaba a integrar un cargo legislativo. Este concejal, Marcelo, era caracterizado por sus compañeros legisladores a través de dos adjetivaciones. En primer lugar, primaban chistes, ironías y quejas por su escasa participación en la cámara legislativa. Manifestaban que siempre estaba de viaje y que atendía las cuestiones gremiales más que el ejercicio de su función como representante del pueblo. En sucesivas entrevistas, él mismo alegaba que el ejercicio de las funciones legislativas quedaba supeditado a su rol como representante sindical. Adornaba esta afirmación reforzando aspectos de su personalidad y estilo de vida tales como su placer por manejar en la ruta con su camioneta, sus ansías por recorrer los yacimientos, viajar por distintos puntos de la provincia y velar por el bienestar de los trabajadores. Sus tareas en la función pública se presentaban como una extensión de la defensa de los derechos de los trabajadores y sus compromisos con el pueblo se ligaban - antes que cualquier otra cosa - a las condiciones de reproducción social. En este sentido, Marcelo reforzaba las apreciaciones que de él se tenían en relación a su desempeño público, ya que creía que su cargo legislativo era producto de una alianza provicial que extendía su liderazgo sindical en el espacio de la villa obrera. Tal como plantean Elias y Scotson (2000) y Goffman (2010 [1963]), la identidad del individuo estigmatizado se sustenta en las mismas creencias que la ideología estigmatizadora.

En segundo lugar, los relatos de sus compañeros en la función pública iban un poco más allá y ponían en circulación, cada vez que les era posible, sospechas de corrupción en las que se veían implicados Marcelo y empresas petroleras que afectaban los derechos de los trabajadores. Sin embargo, esas suspicacias eran descritas de un modo particular. Los legisladores "nacidos y criados" podían describir en qué consistían las dádivas, cómo se habían sucedido los eventos de la negociación pero poco podían decir respecto del origen de los conflictos. El desconocimiento respecto de si se trataba de accidentes de trabajo, motivos que ocasionaron la paralización de la producción, reclamos gremiales, etc., escapaba a la órbita de su comprensión o interés inmediato. Ni siquiera en estos casos, el mundo petrolero se convertía en un objeto de reflexión por su contenido, que permanecía ajeno al rumor. En este sentido, la comidilla también se inscribe en un patrón de interacción social. Lo importante en estos

9 Los pobladores de Buta Ranquil también eligieron a otro foráneo que formaba parte de una lista opositora. Sin embargo, a pocos meses de asumir fue destituido tras la resolución de un juicio en el que fue declarado culpable por haber usurpado con métodos engañosos el terreno de una "nacida y criada" en el pueblo. En su lugar asumió un criancero "nacido y criado” en el pueblo. Aunque el caso amerita un tratamiento particular, nos importa ahora concentrarnos en las categorías de adscripción más que en el devenir de los procesos políticos en particular. 
relatos era remarcar la suspicacia de un comportamiento poco decoroso por parte de una personalidad pública que arruinaba su reputación como hombre moralmente respetable. Tal como plantea Bailey (1971), la "reputación" apela a un "fondo común de conocimiento sobre todos los miembros de una comunidad", en donde es menos una cualidad que posee un hombre y más las opiniones que los otros tienen de él y que permiten indagar no en los actos individuales tomados por sí mismos sino en los patrones de interacción que se revelan por su intermedio.

Las ausencias en las reuniones legislativas sumadas a estos rumores y desconfianzas reforzaban el argumento de que Marcelo estaba "usurpando" un espacio de poder político que se reclamaba como prerrogativa de los nyc, tal y como había sido hasta entonces. En este sentido, coincidimos con Crespo (2008) al decir respecto de estas categorías que señalan una pertenencia al espacio social que supone la legitimidad de un acceso diferencial a los recursos - en este caso, políticos.

"La gente de afuera es como que no ha adquirido mucho protagonismo porque es como que está pensando en hacer la plata e irse más que nada. [...] Es su forma de sobrevivir. Ellos vienen a buscar su sustento y por ahí les cuesta arraigarse al pueblo. Pero hasta tanto no le agarran como cariño al pueblo, es como que están pensando en otra cosa, entonces la gente de acá es la que habla generalmente de política y de los políticos" [Gastón, concejal].

Efectivamente, la política también aparece teñida por las demarcaciones entre un adentro y un afuera. Quien viene de afuera siempre conserva un manto de sospecha y desconfianza porque "vienen a hacer plata pero están pensando en irse". Por otra parte, se produce un contraste de esta mala reputación - de nacimiento - frente a la prerrogativa de los nyc, quienes son autorizados para "hablar de política y de los políticos". ${ }^{10}$ En la explicación de Gastón se condensan los atributos que, informalmente, se constituyen como requisito para anhelar el ejercicio del poder político. Ser un nyc corresponde a una categoría de persona que otorga legitimidad, el no serlo se convierte en un atributo que dificulta el ejercicio del poder. Las categorías parecen operar como condicionantes para poder ser "elegido" y "ejercer el poder". El enraizamiento local parece ser esencial para hacer una carrera política, el "extranjero", el "venido de afuera" tiene que hacerse aceptar porque, como plantea Abélès (1990), el ejercicio del poder transforma al individuo quien deviene en una personalidad

10 No está de más recordar que, originalmente en el mundo romano, los ciudadanos forman parte de una nación en virtud de su nacimiento en un territorio jurídicamente ordenado. La ciudadanía es, antes que nada, un conjunto de derechos adquiridos por nacimiento. 
pública. ${ }^{11}$ Por tanto se espera que encarne los intereses de la colectividad, en la que primero tiene que ser aceptado, hecho que hasta cierto punto parecía no desvelar a Marcelo. La distancia social que se expresa entre quienes son locales y quienes son extranjeros sirve de marco conceptual generalizante para remarcar el acceso diferencial al cargo político y la base de legitimidad que debiera construirse como su intermedio.

Incluso la relación con el intendente, su aliado político, era tensa. Para Marcelo, el intendente "es muy cerrado con las empresas, ejerce políticas totalmente distintas a las que tenemos gremialmente, que es donde tenemos la fuerza”. Efectivamente, mientras el intendente conducía un proceso de evitación respecto de estos "otros petroleros", Marcelo reforzaba políticas gremiales donde la residencia en el pueblo era su principal bandera. A nivel provincial, el gremio centraba su política en la promoción del arraigo en los pueblos. El registro de domicilio en el pueblo se ha convertido en un requisito para el acceso a un puesto de trabajo y las empresas tuvieron la obligación de anular los campamentos en la vera del yacimiento y alquilar hoteles o piezas para albergar a las cuadrillas de trabajadores. Esta política responde a un interés concreto: amplia la base de representación gremial. "Desde que llegué yo, hasta las mucamas de los hoteles están afiliadas al sindicato”, reforzaba Marcelo dando cuentas de esta política expansiva.

Las contradicciones entre el petrolero y el intendente se intensificaron al punto tal que al año de haber asumido en el cargo legislativo, el intendente apeló a sus relaciones con los bloques opositores para que motoricen el relevo de Marcelo al frente del Concejo Deliberante, argumentando sus reiteradas ausencias. Aunque esta iniciativa fracasó, sin embargo puso de relieve las afinidades personales, basadas en las categorías de adscripción. El intendente es un "nacido y criado", miembro de una de las familias más notables en el pueblo y con una trayectoria política que se remonta a varias décadas. Para promover esta "traición" acudió a otro concejal que, aunque opositor, era tenido como un representante de los valores tradicionales del pueblo. Y aunque éste se negó a concretar la destitución de Marcelo, sin embargo reconocía abiertamente que, pese a las diferencias ideológicas e incluso "de clase" con el intendente, ya que provenía de una familia de bajos recursos que había perdido su capital - chivos - tras una helada, era posible mantener una relación cordial, mientas que con Marcelo "es una cuestión de piel". Políticamente, Marcelo entraba en contradicción con el intendente y muchas veces votaba a favor de las posturas que promovían los opositores. Sin embargo, cuando se los comparaba, el estigma de Marcelo echaba por tierra toda valoración positiva. En términos de Goffman (2010 [1963]: 144), Marcelo exponía una 
performance de autenticidad que reforzaba su subjetividad portadora del estigma, ya que como "vocero del grupo" llevaba adelante un "estilo de vida" tal y como era esperable. En ese sentido, las políticas migratorias que conducía como militante sindical para promover la radicación de los trabajadores afiliados al sindicato quedaban relegadas, en tanto con su "estilo de vida" consolidaba una imagen pública que utiliza el lenguaje de sus enemigos (Goffman 2010 [1963]: 145). ${ }^{12}$

En este plano puede plantearse que las alianzas políticas que formalmente se sostienen como productos de un acuerdo provincial entre el partido y el gremio no necesariamente se expresan territorialmente. El desprecio por el sindicalista expresaba un patrón de afinidad sobre el que cultura y política se imbrican más allá de alianzas formales y se aproximan a un fondo común de conocimiento y clasificación que requiere ser compartido. En efecto, las personalidades sociales no siempre se condicen con dichas alianzas y en el proceso político remarcan empatías que no necesariamente se corresponden con ellas. La rivalidad del intendente con el gremialista no se expresa como una disputa abierta sino que requiere movilizar las afinidad personales en función del nacimiento. En este sentido, las alianzas políticas no dejan de ser tales aunque se solapan a las empatías devenidas de la confianza y reconocimiento de las personalidades sociales.

Sin embargo, estas barreras no son infranqueables. Tal como plantea Crespo (2008), en la medida en que estas categorías no actúan solas en el mundo sino que se hayan insertas en entramados conceptuales y mundos materiales sobre las que operan, también tienen algo de flexibles. Los rumores, las adjetivaciones y las desconfianzas para con Marcelo se expresaban públicamente. De hecho, ni siquiera él se esforzaba por responder a los agravios, ya que, por una parte, se encontraba protegido por "una estructura de alianzas políticas provinciales" y, por otra parte, representaba y controlaba un nuevo espacio de poder en la comunidad - el acceso al empleo petrolero. La rivalidad con el intendente provenía de esta nueva fuente de poder: ni Marcelo necesitaba ajustarse al mandato del intendente al pie de la letra, ni su base de construcción política residía en las lógicas municipales sino que su base de construcción política se sustentaba en el acceso y sostenimiento sobre el mundo del trabajo asalariado sobre el que ejerce un control considerable. Por debajo de la mesa, se nos explicaba que incluso miembros del cuerpo legislativo pertenecientes a la oposición preferían mantener buenas relaciones con Marcelo en tanto podía conseguir trabajo para sus parientes.

12 "Cuando el objetivo político último es suprimir la diferencia provocada por el estigma, el individuo puede descubrir que esos mismos esfuerzos son capaces de politizar su propia vida, volviéndola aún más diferente de la vida normal" (Goffman 2010 [1963]: 145). 
De esta manera, la pregunta que nos hicimos al principio de este apartado - ¿de qué manera estos relatos constituyen algo más que una interpretación y permiten sostener que los "nacidos y criados" autoasumen prerrogativas frente a los outsiders? - requiere distinguir entre las categorías de adscripción y el proceso social en el que se ven inmersas. En definitiva, el extranjero no se encuentra ligado a los otros por normas y convenciones locales, se comporta como es esperable que un extranjero lo haga, en tanto no se halla compelido a sujetar su comportamiento a las reglas que el propio grupo de establecidos impone sobre sí mismo. ${ }^{13}$

\section{REFLEXIONES FINALES}

En el presente artículo, priorizamos el punto de vista de los actores como estrategia para dar cuenta de las formaciones culturales específicas sobre las que tiene lugar la desregulación y la disputa entre capital y trabajo, relacionando economía, política y cultura sobre un proceso de cambio social.

Precisamente si hemos trabajado con categorías de adscripción es porque la expansión capitalista a partir de la explotación hidrocarburífera en Buta Ranquil permite dar cuenta de sus "impactos" en los territorios concretos no sólo a partir de desigualdades económicas sino también políticas y simbólicas. Observar y reconstruir la trama a partir de la cual el "petrolero" se instala en la escena política ha sido un ejercicio para dar cuenta de formas de organización social y principios que se ven objetivados tras la irrupción de una actividad económica. Al tomar como punto de partida la forma en que los "butaranquilenses" experimentan el proceso de cambio social, devino central focalizar en los vínculos entre política, economía y cultura, de acuerdo a la forma en que esta relación se expresa, deviene de un modo tal en un territorio concreto y expone el entramado conceptual sobre el que se rigen las relaciones de poder.

Hemos pretendido plantear que la distancia física y la distancia social no son la misma cosa. Una denominación tan genérica como los "butaranquilenses" ha sido puesta en entredicho a partir de la fuerza con la que los procesos políticos ponen en evidencia dicha distancia social. En ese sentido, nos situamos en un enfoque de "comunidad" entendiendo que la misma es producto de una relación social inspirada en un sentimiento subjetivo que no sólo identifica derechos y obligaciones compartidas sino que interpela espacios de construcción de las personalidades sociales, es decir construye

13 Para Park, el emigrante es "un hombre libre, en lo práctico y en lo teórico. Considera su relación con los otros con menos prejuicios; los somete, pues, a un patrón más general y objetivo, y las tradiciones, las costumbres o los afectos no limitan su acción" (en "Racial assimilation in Secondary Groups", citado en Alcalde Campos 201 1: 380). 
una subjetividad basada en supuestos morales y simbólicos que se ponen en relieve frente a contextos de transformación de la sociedad general. En estas páginas hemos subrayado aquel fondo común de conocimiento, aquellas disposiciones y categorías compartidas que sirven para interpretar la expansión petrolera y la irrupción de la organización del trabajo en la política municipal. Al trabajar con categorías de adscripción normalizadas para la sociedad ha sido posible observar su dimensión - la fuerza y los límites de las mismas sobre un proceso de cambio social.

Indagar sobre esta experiencia diferencial nos permitió profundizar en la naturaleza de la organización social de las villas obreras desde la lectura que hacen los sujetos de la misma. En este sentido, la distancia social que señalan las categorías no sólo condensa cierta aversión por lo extraño y cierto sentido de rivalidad política sino que también alude a la experiencia de la desigualdad. En este sentido, las lecturas locales no reproducen discursos, políticas o debates económicos. Pero es importante advertir que no dejan de ser producto de un proceso de dominación que posiciona a los sujetos en condiciones de inferioridad. Los "butaranquilenses" ejercitan lecturas de su vida cotidiana tamizandola en relación a la desdicha que significa sentirse "un pueblo olvidado del norte neuquino". Sobre este tamiz advierten entonces al extranjero como factor de desorden. En todo caso, lo lamentable, finalmente, no es sólo el estigma ni de unos ni de otros sino la imposibilidad de ejercitar una lectura donde los efectos de la dominación - la desigualdad - sitúen en el centro de la escena a las responsabilidades políticas y económicas que excedan al escenario de la interacción social local. 


\section{BIBLIOGRAFÍA}

ABÉLÈS, Marc, 1990, Anthropologie de l'État. París, Armand Colin.

ALCALDE CAMPOS, Rosalina, 2011 , "De los outsiders de Norbert Elias y de otros extraños en el campo de la sociología de las migraciones”, Papers, 96 (2): 375-387.

AZPIAZU, Daniel, 2005, Las Privatizadas: Ayer, Hoy y Mañana, tomo II. Buenos Aires, Editorial Capital Intelectual, colección Claves para Todos.

BAILEY, F. G., 1971, "Gifts and poison”, en F. G. Bailey, Gifts and Poison. Oxford, Basil Blackwell, 1-25.

COlAntuono, María Rosa (coord.), 2001, Petróleo y Desarrollo Local: Centros Norpatagónicos en Busca de Alternativas. Neuquén, Universidad del Comahue.

CRespo, Carolina, 2008, Políticas de la Memoria: Procesos de Patrimonialización de los Recursos Arqueológicos y Construcción Identitaria entre los Mapuches de la Rinconada de Nahuelpán en Río Negro. Buenos Aires, Universidad de Buenos Aires, tesis doctoral en Filosofía y Letras, mimeo.

ELIAS, Norbert, 2003, "Ensayo acerca de las relaciones entre establecidos y forasteros", Revista Española de Investigaciones Sociológicas (REIS), 104: 219-241.

ELIAS, Norbert, y John L. SCOTSON, 2000, Os Establecidos e os Outsiders. Rio de Janeiro, Zahar.

GARCÍA, Analía, 2009, La Moneda del Desierto: El Circuito Hidrocarburífero y la Conformación en Economías de Enclave en la Provincia de Neuquén. Buenos Aires, Universidad de Buenos Aires, tesis de doctorado, mimeo.

GOFFMAN, Irving, 2009 [1959], La Presentación de la Persona en la Vida Cotidiana. Buenos Aires, Amorrortu Editores.

— 2010 [1963], Estigma: La Identidad Deteriorada. Buenos Aires, Amorrortu Editores.

LANDRISCINI, Graciela, y M. Paula LARÍA, 1999, Propuesta de Desarrollo Estratégico para la Microregión de Cutral Co y Plaza Huincul: Informe Final. Neuquén, Facultad de Economía y Administración, Universidad del Comahue.

LOPES, José Sérgio Leite, 1988, A Tecelagem dos Conflitos de Classe na "Cidade das Chaminés", Livro I-O "Sistema Paulista": a Especificidade de uma Forma de Dominação do Padrão "Fábrica com Vila Operária”. Brasilia, Editora Marco Zero, Universidade de Brasília, CNPq.

MANSILlA, Diego, 2007, Hidrocarburos y Política Energética: De la Importancia Estratégica al Valor Económico - Desregulación y Privatización de los Hidrocarburos en Argentina. Buenos Aires, Ediciones del Centro Cultural de la Cooperación (CCC).

RIBEIRO, Gustavo Lins, 1991, Empresas Transnacionais: Um Grande Projeto por Dentro. San Pablo, Editora Marco Zero e Anpocs.

—, 2006, El Capital de la Esperanza: La Experiencia de los Trabajadores en la Construcción de Brasilia. Buenos Aires, Ed. Antropofagia.

SAlviA, Agustín, y Marta PANAIA, 1997, La Patagonia Privatizada. Buenos Aires, Universidad de Buenos Aires, Colección CEA-CBC.

SAYAD, Abdelmalek, 1999 [1993], "Una familia desplazada”, en Pierre Bourdieu (org.), La Miseria del Mundo. Buenos Aires, FCE, 27-39.

TOZZINI, María Alma, 2004, Del Limite Natural a la Frontera Social: Tierras, Linajes y Memoria en Lago Puelo. Buenos Aires, Universidad de Buenos Aires, tesis de licenciatura en Ciencias Antropológicas, mimeo.

WEBER, Max, 2008 [1922], Economía y Sociedad: Esbozo de Sociología Comprensiva. México, FCE. 